\title{
Long non-coding RNAs as prognostic markers in human breast cancer
}

\author{
Hairong Liu'1,2, Juan Li ${ }^{1,3}$, Pratirodh Koirala ${ }^{1,4}$, Xianfeng Ding ${ }^{1,5}$, Binghai Chen ${ }^{1,6}$, \\ Yiheng Wang7, Zheng Wang ${ }^{7}$, Chuanxin Wang ${ }^{3}$, Xu Zhang ${ }^{8}$, Yin-Yuan Mo ${ }^{1,9}$ \\ ${ }^{1}$ Cancer Institute, University of Mississippi Medical Center, Jackson, MS, USA \\ ${ }^{2}$ Department of Oncology, Shandong Provincial Qianfoshan Hospital, Shandong University, Jinan, China \\ ${ }^{3}$ Department of Clinical Laboratory, Qilu Hospital, Shandong University, Jinan, Shangdong Province, China \\ ${ }^{4}$ Department of Biochemistry, University of Mississippi Medical Center, Jackson, MS, USA \\ ${ }^{5}$ College of Life Science, Zhejiang Sci-Tech University, Hangzhou, Zhejiang, China \\ ${ }^{6}$ Department of Urology, Affiliated Hospital of Jiangsu University, Jiangsu, Zhenjiang, China \\ ${ }^{7}$ School of Computing, University of Southern Mississippi, Hattiesburg, MS, USA \\ ${ }^{8}$ Center of Biostatistics and Bioinformatics, Department of Preventive Medicine, University of Mississippi Medical Center, \\ Jackson, MS, USA \\ ${ }^{9}$ Department of Pharmacology/Toxicology, University of Mississippi Medical Center, Jackson, MS, USA \\ Correspondence to: $X \cup$ Zhang, e-mail: xzhang2@umc.edu \\ Yin-Yuan Mo, e-mail:ymo@umc.edu \\ Keywords: IncRNA, prognosis, breast cancer, biomarkers \\ Abbreviations: InCRNA, long non-coding RNA; lincRNA, long intergenic non-coding RNA; TCGA, The Cancer Genome Atlas; OS, \\ overall survival; CNA, copy number alteration \\ Received: January 10, $2016 \quad$ Accepted: February 18, $2016 \quad$ Published: March 01, 2016
}

\section{ABSTRACT}

Long non-coding RNAs (IncRNAs) have been recently shown to play an important role in gene regulation and normal cellular functions, and disease processes. However, despite the overwhelming number of IncRNAs identified to date, little is known about their role in cancer for vast majority of them. The present study aims to determine whether IncRNAs can serve as prognostic markers in human breast cancer. We interrogated the breast invasive carcinoma dataset of the Cancer Genome Atlas (TCGA) at the cBioPortal consisting of 1,000 cases. Among 2,730 IncRNAs analyzed, 577 IncRNAs had alterations ranging from $1 \%$ to $32 \%$ frequency, which include mutations, alterations of copy number and RNA expression. We found that deregulation of 11 IncRNAs, primarily due to copy number alteration, is associated with poor overall survival. At RNA expression level, upregulation of 4 IncRNAs (LINC00657, LINC00346, LINC00654 and HCG11) was associated with poor overall survival. A third signature consists of 9 IncRNAs (LINC00705, LINC00310, LINC00704, LINC00574, FAM74A3, UMODL1-AS1, ARRDC1-AS1, HAR1A, and LINC00323) and their upregulation can predict recurrence. Finally, we selected LINC00657 to determine their role in breast cancer, and found that LINC00657 knockout significantly suppresses tumor cell growth and proliferation, suggesting that it plays an oncogenic role. Together, these results highlight the clinical significance of IncRNAs, and thus, these IncRNAs may serve as prognostic markers for breast cancer.

\section{INTRODUCTION}

The human genome is actively transcribed. Of interest, protein-coding genes only account for $\sim 2 \%$ whereas the rest of transcripts are non-coding RNAs including microRNAs and long non-coding RNAs (lncRNAs) [1]. MicroRNAs have been shown to play an important role in cancer initiation, progression and metastasis, and they may serve as potential biomarkers for cancer diagnosis and prognosis $[2,3]$. Compared to well- 
studied microRNAs, lncRNAs are poorly characterized. To date, an overwhelming number of lncRNAs have been identified [4, 5]. Based on genomic organization and relationship to protein-coding genes, lncRNAs can be classified into five groups [6]: 1) sense; 2); antisense; 3) bidirectional; 4) intronic and 5) intergenic. Since lncRNA research is still at an early stage, the function for the vast majority of lncRNAs remains to be determined yet. In particular, little is known whether lncRNAs can serve as biomarkers for cancer diagnosis and prognosis.

Breast cancer is the second most common cancer in women in the U.S. based on the latest information from American Cancer Society (www.cancer.org). In 2015 about 231,840 new cases of invasive breast cancer will be diagnosed in women and about 40,290 women will die from breast cancer. Breast cancer is a heterogeneous disease with a large number of genetic alterations. For example, six subtypes have been identified based on gene expression profile and the phenotype. They are luminal A, luminal B, tumor enriched with human epidermal growth factor receptor 2 (HER-2), basal-like, normal-like and claudin-low subtype [7-10]. For example, luminal A is the most common subtype characterized by the expression of estrogen receptor (ER), progesterone receptor (PR), Bcl2 and absence of HER-2. It accounts for $50-60 \%$ of the total breast cancer cases $[8,9]$. The luminal B subtype is characterized by the expression of ER, PR and absence of HER-2. They can be differentiated from luminal A subtype on the basis of high Ki-67 staining which indicates higher proliferation rate [11]. The treatment for different subtypes of breast cancer is often different. However, the molecular pathogenesis of breast cancer remains poorly defined due to its heterogeneity. Although expression of group of specific microRNAs can be associated with cancer subtype [12], it is not clear about the role of lncRNAs in this aspect, and their clinical implication remains to be determined yet.

In the present study, we interrogated the breast invasive carcinoma dataset of the Cancer Genome Atlas (TCGA) at cBioPortal, and identified three lncRNA signatures that can predict overall survival (OS) or recurrence. Furthermore, we characterized one lncRNA from the signatures, LINC00657, by knockout and cell culture models and demonstrated that LINC00657 plays an oncogenic role in breast cancer.

\section{RESULTS}

\section{Genetic alterations of IncRNAs and patient overall survival (OS)}

Long non-coding RNAs (lncRNAs) are a very large mixed group of non-coding RNAs that are arbitrarily defined as larger than $200 \mathrm{bp}$ in length [13]. Hence, we performed a primary search starting with 2730 lncRNAs primarily consisting of long intervening non-coding RNAs (lincRNAs) and anti-sense lncRNAs (Table S1).
The cBioPortal recognized 2,553 of them as valid names (Table S2). Although the vast majority of them had no alterations, there were still quite a few lncRNAs with various genetic alterations. For example, 577 lncRNAs had alterations with alteration frequency ranging from $1 \%$ to $32 \%$ (Table S2). Forty five lncRNAs had alterations in $10 \%$ cases or above (Table S2); 10 of them (PVT1, CCAT1, LINC00536, PCAT1, PCAT2, LINC00861, CCDC26, LINC00977, BAALC-AS2 and LINC00535) accounted for a total of $40 \%$ cases (Figure 1A). These lncRNAs were all on chromosome $8 \mathrm{q}$ (Figure S1A) and heavily overlapped, primarily due to copy number alteration (CNA). Among them, PVT1 had the highest frequency (32\%) and the lowest was LINC00535 with $16 \%$ frequency. Of note, not all amplifications led to upregulation; instead only 2 of them, PVT1 and BAALCAS2, had upregulation (Figure S1B). No downregulation or mutations (missense or truncating mutation), were found. Importantly, each of these IncRNAs except for PVT1 revealed significant associations with OS (Table S2). When all 10 lncRNAs were combined, their alterations were also significantly associated with OS (Logrank test $\mathrm{p}=0.0365)$ (Figure 1B).

Since this primary search included all three parameters (mutation, CNA and RNA expression) and most of alterations were due to amplification and upregulation (Figure S1B), we determined whether a single feature is able to predict patient outcomes. This search identified $27 \%$ frequency for CNA alone and they were associated with OS and logrank test $p$ value was 0.00845 (Figure 1C) among 960 samples. However, when expression was used as a sole criterion, none of these $10 \operatorname{lncRNAs}$ was able to predict outcomes with a significant $p$ value (not shown). Of interest, all of them were located on chromosome 8q (from $8 \mathrm{q} 22$ to $8 \mathrm{q} 24$ ) (Table S3).

In this regard, chromosome $8 \mathrm{q} 24$ has been identified in a large scale study as the most frequently amplified region linked to different cancers $[14,15]$. The well-known oncogene Myc is at chromosome 8q24.21. To determine whether these lncRNAs are closely associated with Myc, we chose 2 3 genes from each chromosome band from 8q21.13 to 8q24.3 to search the alternations of putative copy number. The farer from Myc, the smaller the changes of copy number become (Figure S2A \& B), suggesting that 8q24.21 is the center of CNA. Although 8q24 is believed to be a susceptible region, our analysis suggested that CNA for these lncRNAs may involve an entire region from 8q11.1 to $8 \mathrm{q} 24.3$, and it is associated with OS.

\section{Alterations of IncRNAs in RNA expression and $\mathrm{OS}$}

CNA accounts for the large part of genetic alterations, and these data are obtained largely through genomic DNA copy number arrays [16]. Given that deep 
sequencing becomes widely used and it provides more valuable information, we tried to determine whether deregulation of lncRNA expression (RNA-seq) alone can predict patient survival outcomes. A secondary search for significant predictors was performed in 1098 samples. Compared to CNA, alterations of gene expression were less frequent. For example, only 8 lncRNAs were above $10 \%$ alteration frequency and 95 lncRNAs revealed alternations in above 5\% alternation frequency (Table S2). Using Onco Query Language (OQL) EXP>2, we found that 275 of 1098 cases had upregulation for LINC00657, LINC00346, LINC00654 and HCG11; total alteration frequency for these 4 lncRNAs was $26 \%$ (Figure 2A). Unlike the first lncRNA signature primarily due to CNA that all lncRNAs were clustered (Figure 1A), these 4 lncRNAs were well separated (Figure 2B). For example, they were either on different chromosomes or they were at least $29 \mathrm{Mb}$ apart if they are on the same chromosome. Together, the association between lncRNA upregulation and OS was highly significant ( $\mathrm{p}=1.432 \mathrm{e}-$ 5) (Figure 2C). In contrast to the first signature, CNA of these 4 lncRNAs had no association with OS (Figure S3). Individually, LINC00657 revealed 11\% frequency of alterations in 1098 samples and was the highest among these four lncRNAs. Its upregulation was significantly associated with OS (Figure S4A). The upregulation frequency and $\mathrm{p}$ values for the other 3 lncRNAs association with OS were shown in Figure S4B D. Of note, upregulation of these lncRNAs had no association with recurrence (not shown).

\section{A IncRNA signature for recurrence}

Recurrence is a major concern for cancer survivors. Since the first two signatures were not able to predict recurrence, next we searched for a lncRNA signature

$\begin{array}{lll}\text { A } & \text { PVT1 } & 32 \% \\ \text { BAALC-AS2 } & 23 \% \\ \text { CCAT1 } & 21 \% \\ & \text { LINC00536 } & 21 \% \\ \text { PCAT1 } & 20 \% \\ \text { PCAT2 } & 20 \% \\ \text { LINC00861 } & 20 \% \\ \text { CCDC26 } & 19 \% \\ \text { LINC00977 } & 19 \% \\ \text { LINC00535 } & 15 \%\end{array}$

Amplification

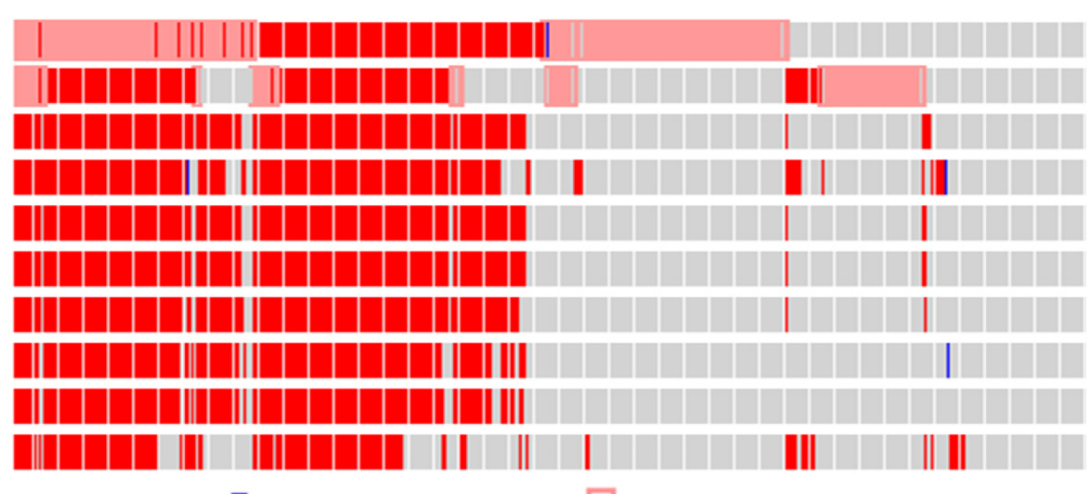

Deep Deletion
mRNA Upregulation

\section{B $\mathrm{CNA}+$ Exp}

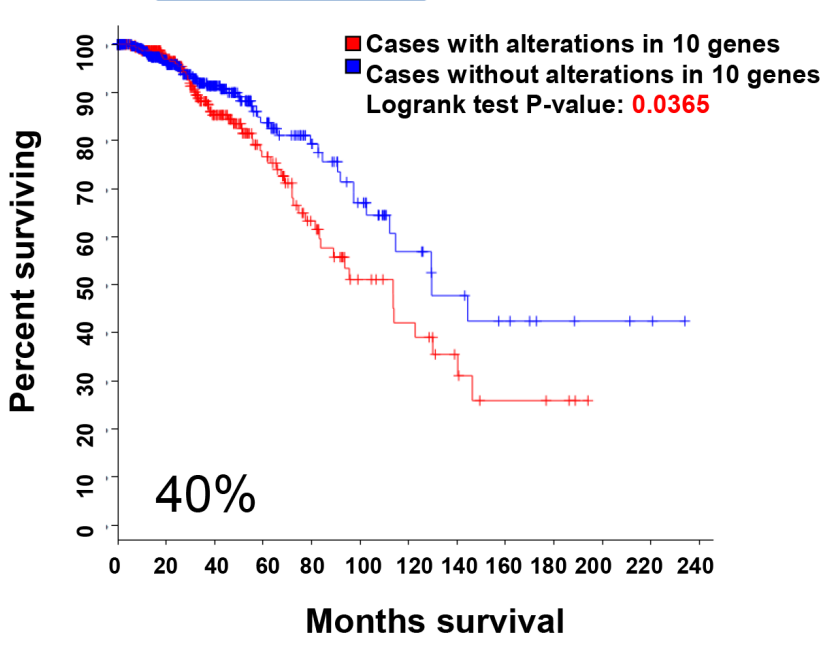

C CNA alone

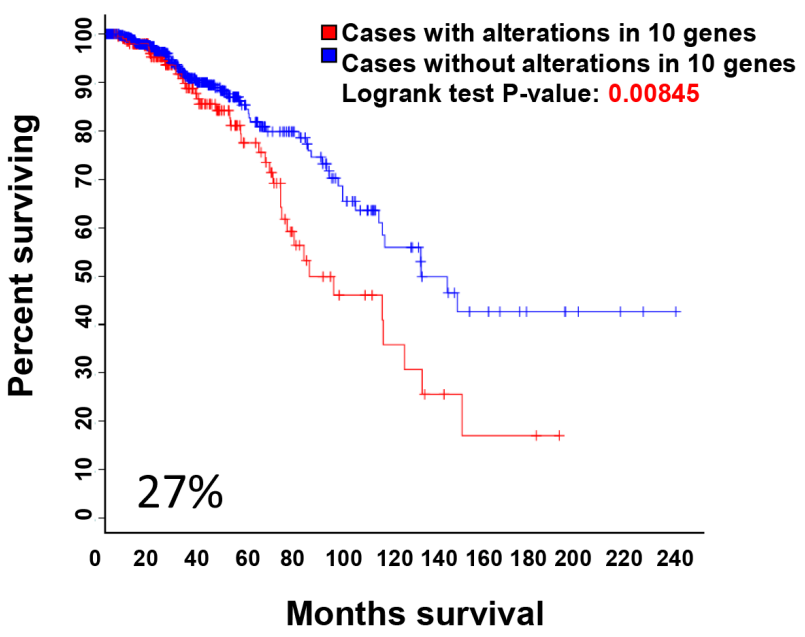

Figure 1: Identification of the first IncRNA signature associated with overall survival. A. Top 10 lncRNAs based on alteration frequency primarily due to CNA and upregulation. B. Kaplan-Meier curve for OS due based on alterations of these 10 lncRNAs (CNA and upregulation). C. Kaplan-Meier curve based on alterations of these 10 lncRNAs (CNA alone). 
for recurrence. There were 68 cases of recurrence in this cohort (Table S4). We found that upregulation of 18 lncRNAs with $\mathrm{p}$ value $<0.05$ was associated with recurrence (Table S5). To determine the optimal number of lncRNAs for prediction of recurrence, we adopted a stepwise forward selection approach based on Cox model to identify lncRNAs significantly associated with recurrence. 1) All variables were individually included in the Cox model on recurrence. The variable with smallest $\mathrm{p}$ value and below the $5 \%$ threshold was first selected. 2) First, the remaining variables were evaluated in the Cox model on recurrence with previously selected variable(s). Next, the variable with smallest $\mathrm{p}$ value and below 5\% threshold entered the model. Finally, if any variable became insignificant after inclusion of the new variable, the insignificant variable was removed. We repeated step 2 until none of the remaining variables having $p$ value less than 0.05.3) All possible models based on the selected variables are evaluated by AIC. The model with the smallest AIC value was determined as the optimal model.

Based on AIC estimation, 9 of 18 lncRNAs were selected as a signature for prediction of recurrence (Figure $3 \mathrm{~A} \& 3 \mathrm{~B})$. Individually, they were upregulated with alteration frequency of $2 \sim 5 \%$, and together about $28 \%$ in a total of 1105 samples (Figure 3A). Thus, this Cox based

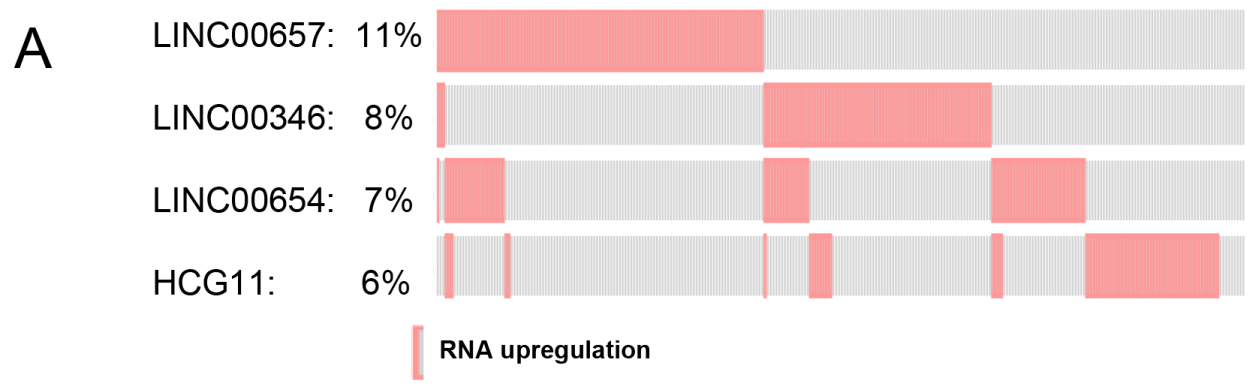

B

\begin{tabular}{l|l|l|l|l|l} 
LncRNA & Location & $\begin{array}{c}\text { Covering region in } \\
\text { genome }\end{array}$ & cDNA (bp) & Accession & Exon \\
\hline LINC00657 & $20 q 11.23$ & $34,633,540-34,638,882$ & 5,343 & NR_027451 1 \\
\hline LINC00346 & $13 q 34$ & $111,516,334-111,522,655$ & 6,322 & NR_027701 1 \\
\hline LINC00654 & $20 p 26.1$ & $5,479,218-5,485,242$ & 3,591 & NR_015406 2 \\
\hline HCG11 & $6 p 22.2$ & $26,521,934-26,527,612$ & 5,688 & NR_026790 1
\end{tabular}

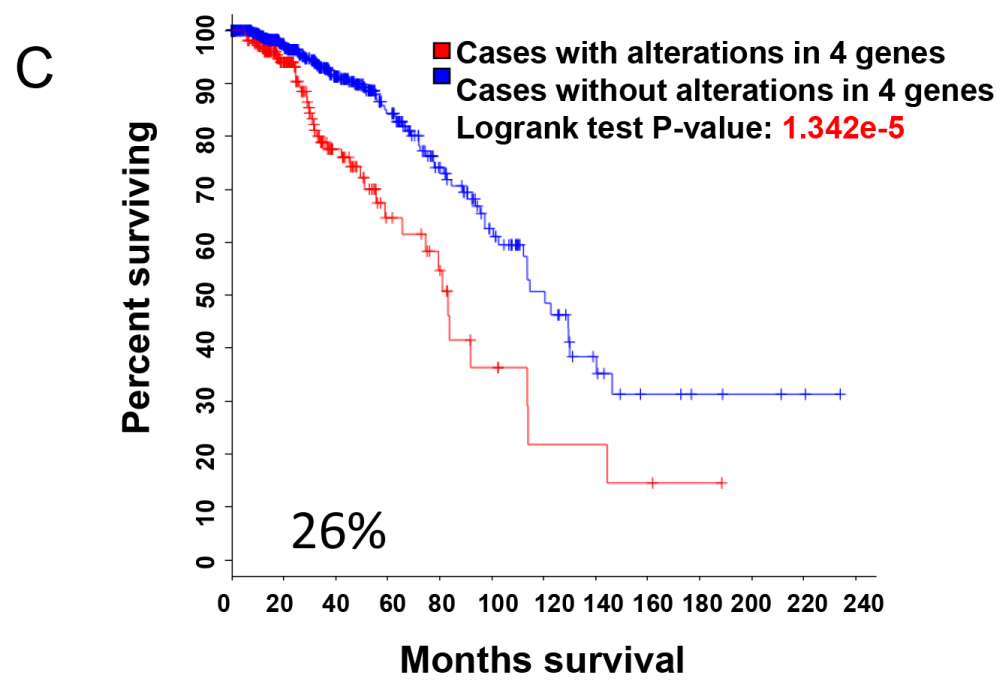

Figure 2: LncRNA signature for OS based on RNA expression. A. Upregulation of LINC00657, LINC00346, LINC00654 and HCG11 with alteration frequency. B. Organizations of these 4 lncRNAs and chromosome locations. C. Upregulation of these 4 lncRNAs is significantly associated with OS as shown by Kaplan-Meier curve. 
search generated a third lncRNA signature consisting of LINC00705, LINC00310, LINC00704, LINC00574, FAM74A3, UMODL1-AS1, ARRDC1-AS1, HAR1A and LINC00323 (Figure 3B). Upregulation of this signature ( $\exp >2.0$ ) was found in 228 of total 943 follow up cases; it was distinctly different from the no upregulation group $(\exp \leq 2.0)$ with Gray's test $p<0.001$ (Figure 3C).

\section{Association of IncRNA signatures with clinicopathologic features}

Based on RNA expression we identified 2 signatures (signature 2 and 3 ) consisting of 13 lncRNAs capable of predicting OS or recurrence. Thus, we determined any association of these lncRNAs with clinicopathologic features including age, tumor stage, metastatic status, ethnicity as well as the stature of ER, PR and HER-2. Among them, we found no significant association with age, tumor stage, metastatic status or ethnicity. However, their expression was associated with HER-2. For example, although expression of signature 2 (LINC00657, LINC00346, LINC00654 and HCG11) was associated with overall survival in both HER-2 positive and HER-2 negative cases, the logrank test P-value was much smaller for HER-positive than for HER-2 negative cases (Figure 4A \& 4B). Furthermore, in HER-2 positive patients 5 year survival rate was about $90 \%$ for cases with upregulation of this signature compared to $\sim 65 \%$. In contrast, in HER-2 negative patients 5 year survival rate was $\sim 85 \%$ for cases with upregulation of this signature compared to $\sim 65 \%$ for cases without upregulation, implying poorer prognosis for HER-2 positive patients with upregulation of this signature than for HER-2 negative patients. For signature 3 we found that 5 year survival rate was about $90 \%$ for cases with upregulation of this signature compared to $\sim 80 \%$ for cases without upregulation (Figure $4 \mathrm{C}$ ). In contrast, in HER-2 negative patients 5 year survival rate was $\sim 90 \%$ for cases with upregulation of this signature compared to $\sim 65 \%$ for cases without upregulation (Figure 4D), suggesting poorer prognosis for HER-2 negative patients with upregulation of this signature.

Next, we examined associations of alterations for individual lncRNAs derived from signature 2 and 3 with ER, HER-2 or triple negative. Based on initial

A

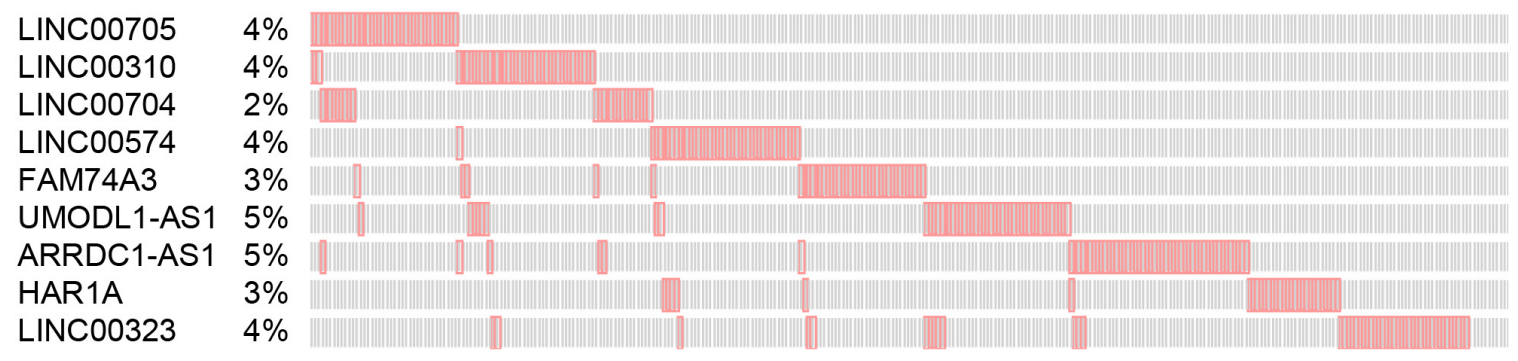

RNA upregulation

B

\begin{tabular}{|r|l|l|}
\hline Step & Variable added & AIC \\
\hline 1 & LINC00705 & 753.1 \\
\hline 2 & LINC00310 & 748.3 \\
\hline 3 & LINC00704 & 743.9 \\
\hline 4 & LINC00574 & 738.8 \\
\hline 5 & FAM74A3 & 732.8 \\
\hline 6 & UMODL1-AS1 & 727.7 \\
\hline 7 & ARRDC1-AS1 & 724.7 \\
\hline 8 & HAR1A & 723.0 \\
\hline 9 & LINC00323 & 719.6 \\
\hline
\end{tabular}

C

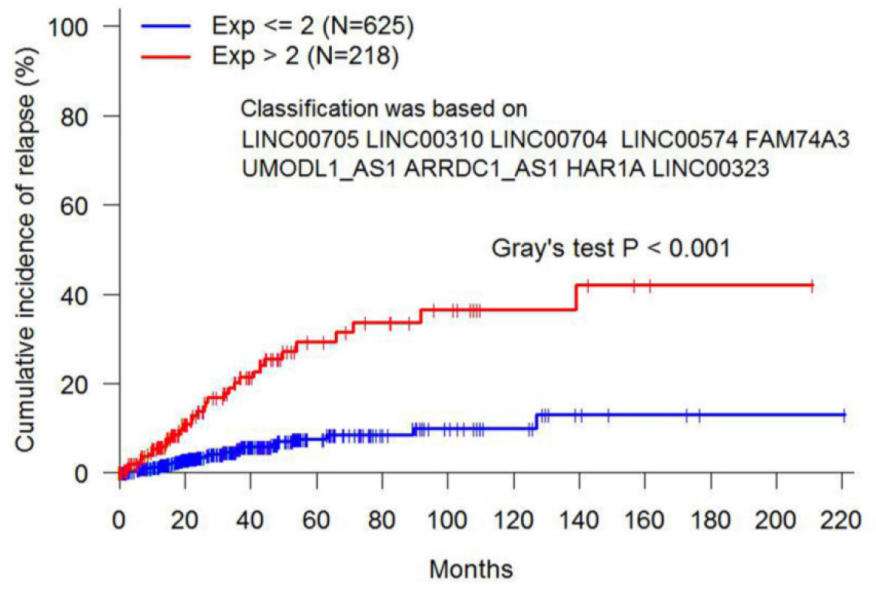

Figure 3: LncRNA signature for recurrence based on RNA expression. A. Upregulation of 9 lncRNAs with alteration frequency. B. Nine lncRNAs are selected as a signature for prediction of recurrence based on AIC estimation. C. Upregulation of these 9 lncRNAs is significantly associated with recurrence. 
p values, 11 of 13 lncRNAs were associated with ER status (Table S6). For example, in ER positive patients, LINC00657 regulation accounted for $60 \%$, but no upregulation accounted for $71 \%$ In HER-2 positive patients, 34\% had upregulation of LINC00654 upregulation accounted for $34 \%$, no upregulation accounted for $66 \%$. In the triple negative group, alteration for each of 6 lncRNAs (HCG11, LINC00310, LINC00704, UMODL1-AS1, ARRDC1-AS1 and HAR1A) was significantly higher than no alteration (Table S6).

Since the alteration frequency for each of these lncRNA varies, along with 3 clinical conditions, to integrate these variations, we applied the Bonferroni correction to control the overall type I error rate at $5 \%$. The Bonferroni-adjusted P-value was calculated by multiplying
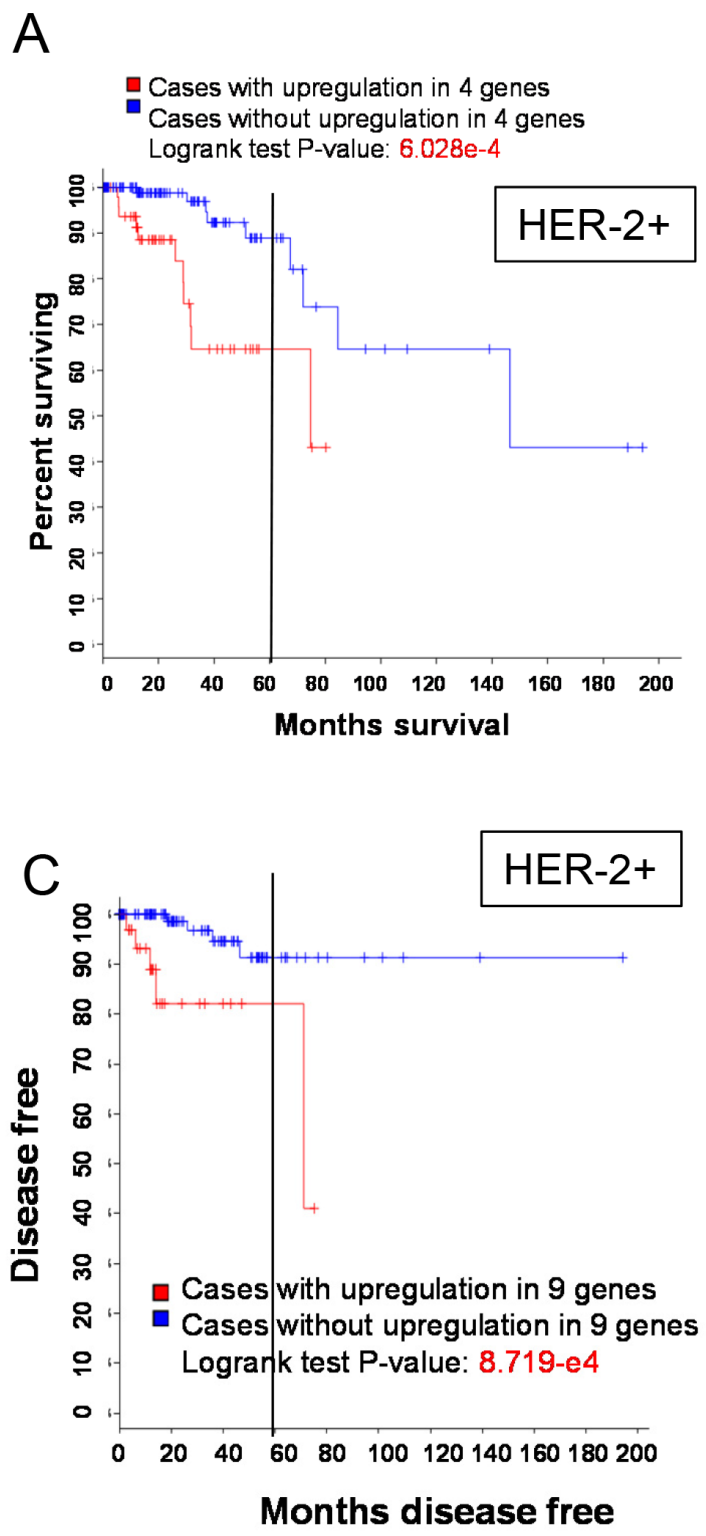

the raw P-value by 39 . Table 1 shows the adjusted P-values for associations between alterations of lncRNAs and ER, HER-2 and triple negative status. After adjustment, none of the lncRNAs was significantly associated with HER-2 status. HCG11 and UMODL1-AS1 were both significantly associated with ER and triple negative status. Status of ER was also significantly associated with a few other lncRNAs, including LINC00346, LINC00654, LINC00704, and ARRDC1-AS1.

\section{LINC00657 is a potential oncogenic gene}

Upregulation of these lncRNAs is associated with overall survival or recurrence, suggesting that they may play an oncogenic role. Hence, we selected LINC00657
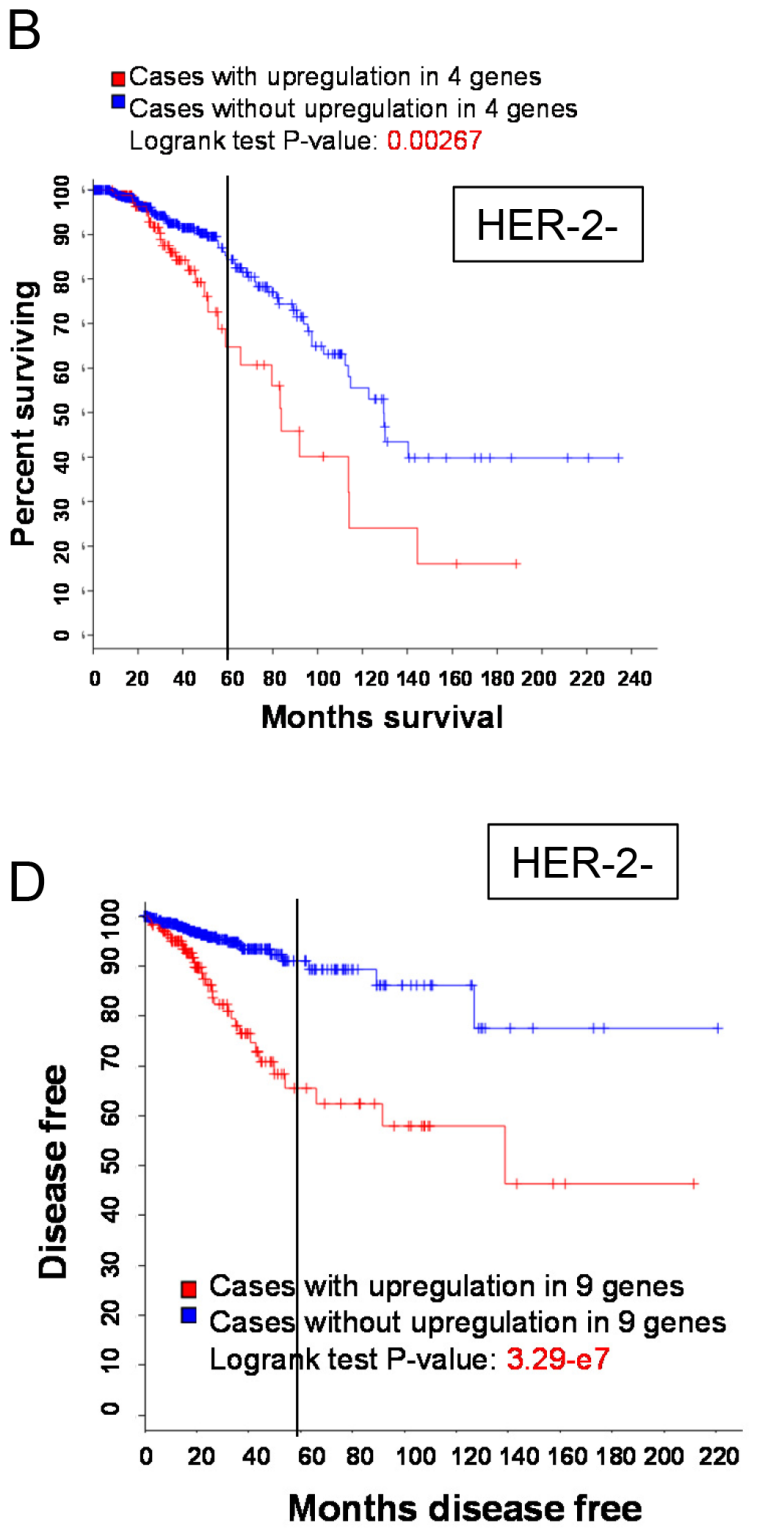

Figure 4: HER-2 status and OS or recurrence. A \& B. A poorer OS with upregulation of signature 2 in HER-2 positive patients than in HER-2 negative patients. C \& D. A higher recurrence with upregulation of signature 3 in HER-2 negative patients than in HER-2 positive patients. 
Table 1: Alterations of IncRNAs associated with ER, PR and HER-2

\begin{tabular}{|c|c|c|c|c|c|c|c|}
\hline & & \multicolumn{2}{|c|}{ ER } & \multicolumn{2}{|c|}{ HER-2 } & \multicolumn{2}{|c|}{ Triple negative } \\
\hline & & Positive N (\%) & $\begin{array}{c}\text { Bonferroni- } \\
\text { adjusted } \\
P \text { value }\end{array}$ & $\begin{array}{c}\text { Positive N } \\
(\%)\end{array}$ & $\begin{array}{c}\text { Bonferroni- } \\
\text { adjusted } \\
P \text { value }\end{array}$ & $\begin{array}{c}\text { Positive N } \\
(\%)\end{array}$ & $\begin{array}{c}\text { Bonferroni- } \\
\text { adjusted } \\
P \text { value }\end{array}$ \\
\hline \multirow[t]{2}{*}{ LINC00657 } & $\begin{array}{l}\text { Alteration } \\
(\mathrm{N}=114)\end{array}$ & $68(60 \%)$ & 0.479 & $21(18 \%)$ & 1.000 & $20(18 \%)$ & 1.000 \\
\hline & $\begin{array}{l}\text { No alteration } \\
(\mathrm{N}=845)\end{array}$ & $603(71 \%)$ & & $164(19 \%)$ & & $163(27 \%)$ & \\
\hline \multirow[t]{2}{*}{ LINC00346 } & $\begin{array}{l}\text { Alteration } \\
(\mathrm{N}=72)\end{array}$ & $14(19 \%)$ & $<0.0001$ & $10(14 \%)$ & 1.000 & $16(22 \%)$ & 1.000 \\
\hline & $\begin{array}{l}\text { No alteration } \\
(\mathrm{N}=887)\end{array}$ & $657(74 \%)$ & & $175(20 \%)$ & & $167(19 \%)$ & \\
\hline \multirow[t]{2}{*}{ LINC00654 } & $\begin{array}{l}\text { Alteration } \\
(\mathrm{N}=67)\end{array}$ & $23(34 \%)$ & $<0.0001$ & $23(34 \%)$ & 0.129 & $13(19 \%)$ & 1.000 \\
\hline & $\begin{array}{l}\text { No alteration } \\
(\mathrm{N}=892)\end{array}$ & $648(73 \%)$ & & $165(18 \%)$ & & $170(19 \%)$ & \\
\hline \multirow[t]{2}{*}{ HCG11 } & $\begin{array}{l}\text { Alteration } \\
(\mathrm{N}=55)\end{array}$ & $14(25 \%)$ & $<0.0001$ & $7(13 \%)$ & 1.000 & $33(60 \%)$ & $<0.0001$ \\
\hline & $\begin{array}{l}\text { No alteration } \\
(\mathrm{N}=904)\end{array}$ & $657(73 \%)$ & & $178(20 \%)$ & & $150(16 \%)$ & \\
\hline \multirow[t]{2}{*}{ LINC00705 } & $\begin{array}{l}\text { Alteration } \\
(\mathrm{N}=29)\end{array}$ & $14(48 \%)$ & 0.514 & $4(14 \%)$ & 1.000 & $9(31 \%)$ & 1.000 \\
\hline & $\begin{array}{l}\text { No alteration } \\
(\mathrm{N}=930)\end{array}$ & $657(70 \%)$ & & $181(19 \%)$ & & $174(19 \%)$ & \\
\hline \multirow[t]{2}{*}{ LINC00310 } & $\begin{array}{l}\text { Alteration } \\
(\mathrm{N}=36)\end{array}$ & $18(50 \%)$ & 0.565 & $5(14 \%)$ & 1.000 & $15(41 \%)$ & 0.063 \\
\hline & $\begin{array}{l}\text { No alteration } \\
(\mathrm{N}=923)\end{array}$ & $653(71 \%)$ & & $180(20 \%)$ & & $168(19 \%)$ & \\
\hline \multirow[t]{2}{*}{ LINC00704 } & $\begin{array}{l}\text { alteration } \\
(\mathrm{N}=19)\end{array}$ & $2(11 \%)$ & $<0.0001$ & $7(37 \%)$ & 1.000 & $8(42 \%)$ & 0.653 \\
\hline & $\begin{array}{l}\text { No alteration } \\
(\mathrm{N}=940)\end{array}$ & $669(71 \%)$ & & $178(19 \%)$ & & $175(19 \%)$ & \\
\hline \multirow[t]{2}{*}{ LINC00574 } & $\begin{array}{l}\text { Alteration } \\
(\mathrm{N}=36)\end{array}$ & $31(86 \%)$ & 1.000 & $4(11 \%)$ & 1.000 & $3(8 \%)$ & 1.000 \\
\hline & $\begin{array}{l}\text { No alteration } \\
(\mathrm{N}=923)\end{array}$ & $640(69 \%)$ & & $181(20 \%)$ & & $180(20 \%)$ & \\
\hline \multirow[t]{2}{*}{ FAM74A3 } & $\begin{array}{l}\text { Alteration } \\
(\mathrm{N}=36)\end{array}$ & $25(69 \%)$ & 1.000 & $4(11 \%)$ & 1.000 & $6(17 \%)$ & 1.000 \\
\hline & $\begin{array}{l}\text { No alteration } \\
(\mathrm{N}=923)\end{array}$ & $646(70 \%)$ & & $181(20 \%)$ & & $177(19 \%)$ & \\
\hline \multirow[t]{2}{*}{$\begin{array}{l}\text { UMODL1- } \\
\text { AS1 }\end{array}$} & $\begin{array}{l}\text { Alteration } \\
(\mathrm{N}=42)\end{array}$ & $17(40 \%)$ & 0.002 & $3(11 \%)$ & 1.000 & $18(43 \%)$ & 0.014 \\
\hline & $\begin{array}{l}\text { No alteration } \\
(\mathrm{N}=917)\end{array}$ & $654(71 \%)$ & & $182(20 \%)$ & & $165(18 \%)$ & \\
\hline
\end{tabular}

(Continued) 


\begin{tabular}{|c|c|c|c|c|c|c|c|}
\hline & & \multicolumn{2}{|c|}{ ER } & \multicolumn{2}{|c|}{ HER-2 } & \multicolumn{2}{|c|}{ Triple negative } \\
\hline & & Positive N (\%) & $\begin{array}{c}\text { Bonferroni- } \\
\text { adjusted } \\
P \text { value }\end{array}$ & $\begin{array}{c}\text { Positive N } \\
\text { (\%) }\end{array}$ & $\begin{array}{c}\text { Bonferroni- } \\
\text { adjusted } \\
P \text { value }\end{array}$ & $\begin{array}{c}\text { Positive N } \\
\text { (\%) }\end{array}$ & $\begin{array}{c}\text { Bonferroni- } \\
\text { adjusted } \\
P \text { value }\end{array}$ \\
\hline \multirow[t]{2}{*}{$\begin{array}{l}\text { ARRDC1- } \\
\text { AS1 }\end{array}$} & $\begin{array}{l}\text { Alteration } \\
(\mathrm{N}=31)\end{array}$ & $12(39 \%)$ & $<0.0001$ & $4(13 \%)$ & 1.000 & $13(42 \%)$ & 1.000 \\
\hline & $\begin{array}{l}\text { No alteration } \\
(\mathrm{N}=928)\end{array}$ & $659(71 \%)$ & & $184(20 \%)$ & & $170(18 \%)$ & \\
\hline \multirow[t]{2}{*}{ LINC00323 } & $\begin{array}{l}\text { Alteration } \\
(\mathrm{N}=37)\end{array}$ & $24(65 \%)$ & 1.000 & $4(11 \%)$ & 1.000 & $10(27 \%)$ & 1.000 \\
\hline & $\begin{array}{l}\text { No alteration } \\
(\mathrm{N}=922)\end{array}$ & $647(70 \%)$ & & $181(20 \%)$ & & $173(19 \%)$ & \\
\hline \multirow[t]{2}{*}{ HAR1A } & $\begin{array}{l}\text { Alteration } \\
(\mathrm{N}=26)\end{array}$ & $24(92 \%)$ & 0.346 & $3(12 \%)$ & 1.000 & $1(3 \%)$ & 1.000 \\
\hline & $\begin{array}{l}\text { No alteration } \\
(\mathrm{N}=933)\end{array}$ & $647(69 \%)$ & & $182(19 \%)$ & & $182(19 \%)$ & \\
\hline
\end{tabular}

to determine its effect on breast cancer because alteration of LINC00657 with RNA expression occurred at 11\% frequency, the highest among the 4 lncRNA signature (Figure 2A). Moreover, LINC00657 has been recently shown to play a role in genomic stability [17]. To this end, we first profiled breast cancer cDNA arrays from OriGene consisting of 43 tumor and 5 normal. In 9 of 43 samples (21\%) LINC00657 expression level was above a 2-fold of the mean expression level (Figure 5A). Consistent with this finding, we found that LINC00657 was also upregulated in breast cancer cell lines MCF-7 and MDAMB-231 cells as compared to non-malignant HMLE cells (Figure 5B).

Therefore, we knocked out LINC00657 by CRISPR/ Cas9 system (Figure S5) in LM-4142, a derivative cell line from MDA-MB-231 [18]. We selected two of them for further characterization (Figure 5C, RT-PCR data). MTT assays indicated that LINC00657 KO caused significant reduction of cell growth (Figure 5D). Consistent with this result, clonogenic assays indicated that the number of colonies was much smaller in $\mathrm{KO}$ cells than in vector control (Figure 5E). These results suggest that LINC0657 impacts tumor cell proliferation and cell growth and thus, LINC00657 is a potential oncogene gene.

\section{DISCUSSION}

Despite large numbers of human lncRNAs identified so far, little is known whether they can serve as markers for cancer diagnosis/prognosis. The present study focus on a special group of IncRNAs from HGNC to interrogate the breast invasive carcinoma dataset (provisional) at the cBioPortal. This dataset consists of 960 complete tumor samples and over 1000 samples with RNA expression (RNA-seq) data. From over 2700 lncRNAs we identify three specific lncRNA signatures: 1) lncRNA signature based on alterations of CNA and RNA expression that is associated with OS; 2) IncRNA signature based on alterations of RNA expression alone that is associated with OS; and 3) lncRNAs based on alternations of RNA expression alone that is associated with recurrence. Together, our study suggests that lncRNAs are potential prognostic markers for breast cancer and thus further investigations of these lncRNAs are warranted.

Early work of biomarker discovery in breast cancer focuses on protein-coding genes such as Ki-67, ER, PR, and HER-2 [19]. For example, expression of ER $\alpha$ is a well-established prognostic factor in breast cancer patients [20]. Other molecular biomarkers include p53, p14 ${ }^{\mathrm{ARF}}$, cyclin D1, cyclin E, TBX2/3, and VEGF [21] and genetic mutations such as BRCA1 and BRCA2 [22]. Furthermore, several multigene signature have been developed in recent years to predict risk of breast cancer recurrence after a primary diagnosis $[23,24]$. In particular, Oncotype-Dx, (Genomic Health) consisting of 21 genes, can provide treatment recommendations in conjunction with risk of recurrence [25]. Compared to protein-coding genes, the number of lncRNAs is much larger [26], and thus, lncRNAs should be a rich source for biomarker discovery. Therefore, potential IncRNA signatures would at least complement the existing biomarkers, providing additional information that may help improve the predictability.

Interrogation of this dataset provides a new perspective on the role of lncRNAs as biomarkers for breast cancer diagnosis prognosis. Although early studies have shown that lncRNAs may serve as prognostic markers, their functional role in prognosis may vary even with the same lncRNA. HOTAIR is one of the early identified lncRNAs and plays a significant role in gene regulation through remodeling chromatin structures [27]. 
Importantly, elevated expression of HOTAIR was reported in both primary and metastatic breast cancer and it is a significant predictor of subsequent metastasis and death [28]. Moreover, Sorensen et al showed that HOTAIR is a prognostic marker of metastasis in ER positive breast cancer from 164 patients by microarray analysis [29]. However, Gokmen-Polar et al [30] reported that HOTAIR was only a poor prognostic indicator in ER negative breast cancer from 952 patients in TCGA database. In contrast, high HOTAIR expression had lower risks of relapse and mortality than those with low HOTAIR expression through 336 breast cancer patients [31]. Several possibilities may contribute to the conflicting results. First, detection methods are different in these studies, including qRT-PCR, microarray analysis and HOX tiling array. Second, the cutoff value of high and low HOTAIR expression as well as ER status in these studies may be different. Third, there is a significant heterogeneity in these studies, such as the races, the tumor sizes and the clinical stages. These factors may also explain why HOTAIR does not meet the cut as a prognostic marker in our study. Alternatively, the signatures identified in this study may be more potentially as diagnostic markers than HOTAIR.

Although the role of these lncRNAs within three signatures in breast cancer remains to be determined yet, their association with cancer death or recurrence may
A

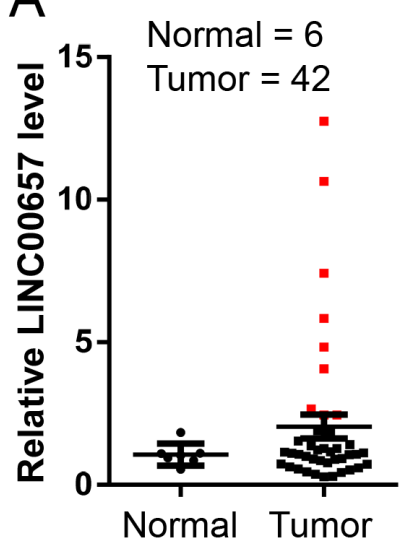

D

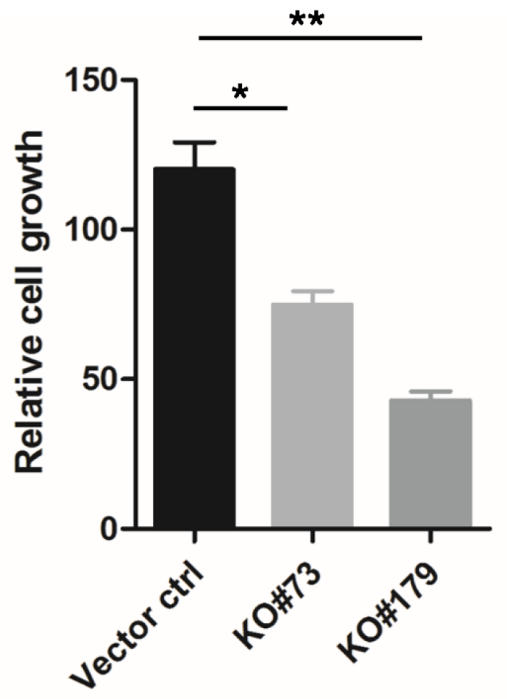

B

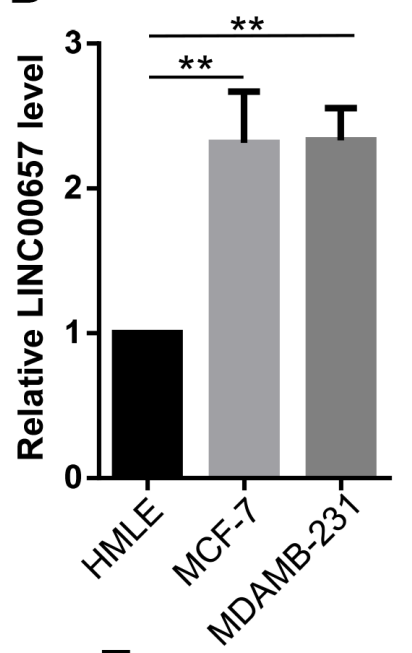

E
C

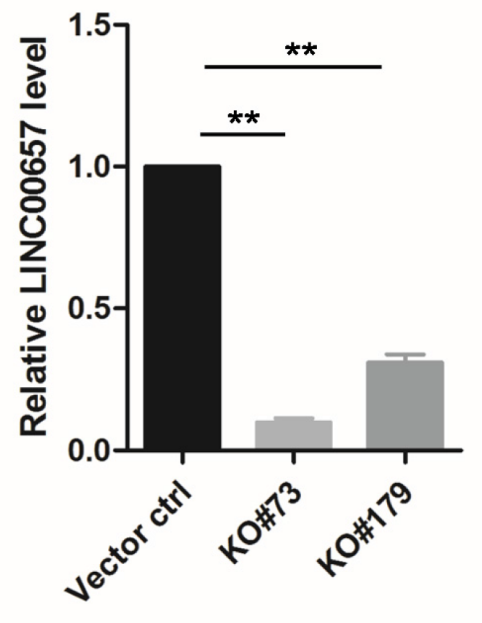

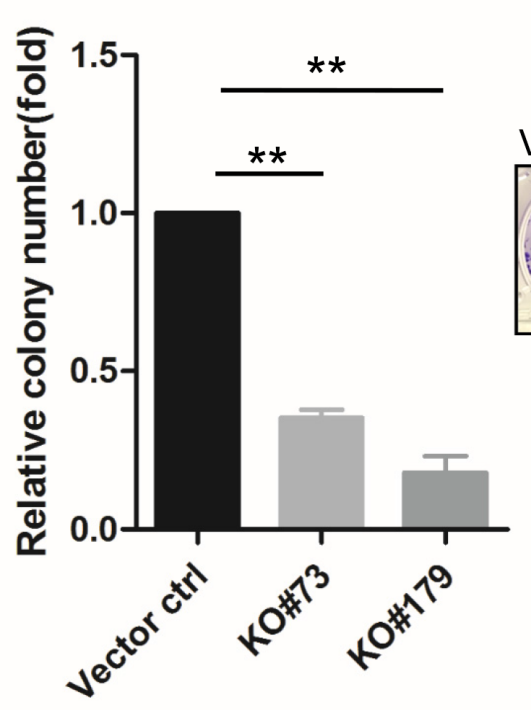

Figure 5: Upregulation of LINC00657 in breast cancer and its promotion of cell growth and proliferation. A. Expression of LINC00657 in the OriGene breast cancer tissue cDNA array, as determined by qPCR. B. LINC00657 is upregulated in breast cancer cells (MCF-7 and MDA-MB-231) as compared to non-malignant breast cells (HMLE). C. Expression of LINC00657 in KO cells as compared to vector control. D \& E. LINC00657 KO suppresses cell growth, as detected by MTT assays and colony formation, as detected by clonogenic assays. Values in B, C, D, E and F are SEM $(\mathrm{n}=3)$. $^{*}, \mathrm{p}<0.05 ; * *, \mathrm{p}<0.01$. 
suggest that they play an oncogenic role. Since the first signature consists of lncRNAs primarily due to CNA, they are clustered in close association with Myc. Thus, the possible oncogenic role, if any, is likely from Myc. In particular, not all amplification cases cause upregulation of their corresponding lncRNAs. On the other hand, both the second and third signatures consist of lncRNAs solely due to upregulation and they are well separated, and the upregulation of these IncRNAs may suggest that they may function as drivers. In support of this notion, we showed that LINC00657 may play an oncogenic role. For example, LINC00657 KO suppresses cell growth and proliferation. Thus, LINC00657 may serve as not only a biomarker, but also a potential therapeutic target.

Given the clinical potential of these lncRNAs identified in this this study, it would be interesting to determine whether they can also be detected in the circulation system. In support of this possibility, recent studies suggest that serum lncRNAs may serve as potential biomarkers for hepatocellular carcinoma and breast cancer [32-34]. In addition, IncRNAs can also be present in urine. For example, prostate cancer antigen 3 (PCA3 or DD3) is a lncRNA that is highly overexpressed in prostate cancer. In particular, presence of PCA3 in urine can predict prostate biopsy outcome [35]. Therefore, further characterization of them is warranted.

Finally, in addition to biomarker discovery, this study provides an example of how researchers with little knowledge in bioinformatics can utilize the existing public data for IncRNA research. Given the overwhelming number of IncRNAs, a challenge for average research laboratories is how to focus on lncRNAs with clinical relevance. The cBioPortal might be a good start point before launching real experiments. The portal currently contains data from 105 cancer genomics studies and a variety of cancer types. Since the dataset we used in this study is still provisional, the number of samples keep increasing. We expect that this may further enhance the predictability in future.

\section{MATERIALS AND METHODS}

\section{Database search}

The cBioPortal (http://www.cbioportal.org) is an open-access resource for interactive exploration of multidimensional cancer genomics data sets, currently providing access to data from more than 5,000 tumor samples from 105 cancer studies in the TCGA pipeline [36, 37]. Although there are overwhelming numbers of human lncRNAs reported from databases, the nomenclature of lncRNAs is still incomplete. In this study we focused on those lncRNAs by HUGO gene nomenclature committee (HGNC) (http://www.genenames.org/) where we downloaded a total of 2730 lncRNAs (http://www .genenames.org/cgi-bin/statistics) (Table S1) for our analysis when this study was initiated.
Genomic data types integrated by cBioPortal included somatic mutations, DNA copy number alterations (CNAs), mRNA and microRNA expression, DNA methylation, protein abundance, and phosphoprotein abundance. The portal contained several sets of samples for breast cancer. From Breast Invasive Carcinoma dataset (TCGA, provisional) as shown in Figure S6, we chose 1) "All complete tumors with 960 samples (when the primary search was performed) or 2) tumors with mRNA data (RNAseq V2) from 1098 or 1105 samples. The primary search parameters included mutations, CNA from GISTIC and mRNA expression (RNA seq data) with the default setting. For the secondary search, we focused on RNA seq data.

\section{Statistical analysis}

All available lncRNAs were sorted by alteration frequency at the cBioPortal. Those lncRNAs with significant log-rank $\mathrm{p}$ values were entered the candidate pool to be considered for further selection. The forward selection was performed among the pool of candidates by using the Cox model on progression. The Akaike information criterion (AIC) was further evaluated for the models that were finalized at each step of forward selection. The model with smallest AIC value was chosen as the final model and the lncRNAs in the final model were identified as predictors of progression. The study cohort of breast cancer patients were divided into those with high expression on any of the predictors and those with normal expressions on these predictors. Progression and death without progression were treated as competing risks. The cumulative incidence of progression was estimated in the aforementioned two patient subgroups. The difference in cumulative incidence of progression between two subgroups was evaluated by the Gray's test [38]. P values less than 5\% were determined as significant. The statistical analyses were performed using the SAS software (version 9.3, the SAS institute) and R package "cmprsk" for competing risks analysis.

\section{Cell culture}

LM-4142 cells originally derived from MDAMB-231 were kindly provided by Dr. Joan Massagué (Memorial Sloan-Kettering Cancer Center) as described previously [18]. Cells were cultured in RPMI-1640 medium with $10 \%$ FBS and $2 \mathrm{mM}$ glutamine. All culture media were supplemented with 100 units $/ \mathrm{mL}$ penicillin and $100 \mu \mathrm{g} / \mathrm{mL}$ streptomycin.

\section{qRT-PCR}

Total RNA was isolated using Direct-zol ${ }^{\mathrm{TM}}$ RNA MiniPrep Kit (Zymo Research, Irvine, CA) as suggested by manufacturer. Reverse transcription was carried out by using RevertAid Reverse Transcriptase (Fisher Scientific) and random primer mix (New England BioLabs, Ipswich, 
MA). The expression of IncRNAs was detected by quantitative RT-PCR (qRT-PCR) using SYBR Green method. Analysis of qRT-PCR was performed as described previously [39].

\section{Construction of plasmids}

The high fidelity Phusion enzyme from Fisher Scientific (Pittsburgh, PA, USA) was used to amplify DNA fragments by PCR for cloning purpose. Dual gRNA targeting the entire exon of LINC00657 and the corresponding donor were constructed using the same method as described previously [40]. Dual gRNA was designed using WU-CRISPR [41] and their sequences were listed in Table S1. To increase the frequency of selection of complete knockout clones, we constructed a donor vector carrying left and right arm homologous to the flanking regions of the targeting sites. PCR was performed using human genomic DNA as a template and primer sets LINC00657-left-Spe I-5.1 and LINC00657-left-Spe I-3.1 (left arm), and LINC00657right-Sal I-5.1 and LINC00657-right-Sal I-5.1 (right arm). These two fragments were sequentially cloned into donor vector at Spe I and Sal I sites as described previously [40]. All amplified fragments were verified by DNA sequencing.

\section{Knockout of LINC00657}

LINC00657 has a single exon with $5,378 \mathrm{bps}$ in length. We used a dual gRNA approach [40] to knock out LINC00657 by CRISPR/Cas9 system [42]. A donor vector carrying $\sim 700$ bp left or right arm derived from the outside regions of LINC00657 was used to facilitate selection of knockout (KO) clones. The dual gRNA construct carrying Cas9 and donor vector were introduced into LM-4142 cells, respectively, by transient transfection. As a control, everything was same except that the dual gRNA is an empty vector. One week later, the transfected cells were subject to puromycin selection; and surviving cells were sorted by FACS based on GFP signal into 96-well plates and then expanded. Initial identification of knockout clones was carried out by genomic PCR, followed by qRTPCR, as described previously [40].

\section{MTT assays}

MTT assay was performed to determine the effect of LINC00657 on cell growth in 96-welll plates as described previously [43].

\section{Clonogenic assays}

To determine the clonogenic survival of LINC00657 $\mathrm{KO}$ cells, cells from either vector control or LINC00657 $\mathrm{KO}$ were seeded on 6-well plates at 1,000 cells/well. At 10 days after seeding, colonies were fixed and stained with $0.1 \%$ crystal violet.

\section{ACKNOWLEDGMENTS}

This work was supported by NIH grant R01 CA154989 (YM) and NSF EPSCoR Seed Grant (ZW and YM).

\section{CONFLICTS OF INTEREST}

The authors declare no conflicts of interest.

\section{REFERENCES}

1. Kung JT, Colognori D, Lee JT. Long noncoding RNAs: past, present, and future. Genetics. 2013; 193:651-669.

2. Etheridge A, Lee I, Hood L, Galas D, Wang K. Extracellular microRNA: a new source of biomarkers. Mutation research. 2011; 717:85-90.

3. Schultz NA, Dehlendorff C, Jensen BV, Bjerregaard JK, Nielsen KR, Bojesen SE, Calatayud D, Nielsen SE, Yilmaz M, Hollander NH, Andersen KK, Johansen JS. MicroRNA biomarkers in whole blood for detection of pancreatic cancer. Jama. 2014; 311:392-404.

4. Xie C, Yuan J, Li H, Li M, Zhao G, Bu D, Zhu W, Wu W, Chen R, Zhao Y. NONCODEv4: exploring the world of long non-coding RNA genes. Nucleic acids research. 2014; 42:D98-103.

5. Volders PJ, Verheggen K, Menschaert G, Vandepoele K, Martens L, Vandesompele J, Mestdagh P. An update on LNCipedia: a database for annotated human lncRNA sequences. Nucleic acids research. 2015; 43:4363-4364.

6. Ponting CP, Oliver PL, Reik W. Evolution and functions of long noncoding RNAs. Cell. 2009; 136:629-641.

7. Sorlie T, Tibshirani R, Parker J, Hastie T, Marron JS, Nobel A, Deng S, Johnsen H, Pesich R, Geisler S, Demeter J, Perou CM, Lonning PE, Brown PO, Borresen-Dale AL, Botstein D. Repeated observation of breast tumor subtypes in independent gene expression data sets. Proceedings of the National Academy of Sciences of the United States of America. 2003; 100:8418-8423.

8. Sorlie T, Perou CM, Tibshirani R, Aas T, Geisler S, Johnsen $\mathrm{H}$, Hastie T, Eisen MB, van de Rijn M, Jeffrey SS, Thorsen T, Quist H, Matese JC, Brown PO, Botstein D, Lonning $\mathrm{PE}$, et al. Gene expression patterns of breast carcinomas distinguish tumor subclasses with clinical implications. Proceedings of the National Academy of Sciences of the United States of America. 2001; 98:10869-10874.

9. Perou CM, Sorlie T, Eisen MB, van de Rijn M, Jeffrey SS, Rees CA, Pollack JR, Ross DT, Johnsen H, Akslen LA, Fluge O, Pergamenschikov A, Williams C, Zhu SX, Lonning PE, Borresen-Dale AL, et al. Molecular portraits of human breast tumours. Nature. 2000; 406:747-752. 
10. Eroles P, Bosch A, Perez-Fidalgo JA, Lluch A. Molecular biology in breast cancer: intrinsic subtypes and signaling pathways. Cancer treatment reviews. 2012; 38:698-707.

11. Cheang MC, Chia SK, Voduc D, Gao D, Leung S, Snider J, Watson M, Davies S, Bernard PS, Parker JS, Perou CM, Ellis MJ, Nielsen TO. Ki67 index, HER2 status, and prognosis of patients with luminal B breast cancer. Journal of the National Cancer Institute. 2009; 101:736-750.

12. Radojicic J, Zaravinos A, Vrekoussis T, Kafousi M, Spandidos DA, Stathopoulos EN. MicroRNA expression analysis in triple-negative (ER, PR and Her2/neu) breast cancer. Cell Cycle. 2011; 10:507-517.

13. Wright MW. A short guide to long non-coding RNA gene nomenclature. Human genomics. 2014; 8:7.

14. Fromont G, Godet J, Peyret A, Irani J, Celhay O, Rozet F, Cathelineau X, Cussenot O. 8q24 amplification is associated with Myc expression and prostate cancer progression and is an independent predictor of recurrence after radical prostatectomy. Human pathology. 2013; 44:1617-1623.

15. Guan Y, Kuo WL, Stilwell JL, Takano H, Lapuk AV, Fridlyand J, Mao JH, Yu M, Miller MA, Santos JL, Kalloger SE, Carlson JW, Ginzinger DG, Celniker SE, Mills GB, Huntsman DG, et al. Amplification of PVT1 contributes to the pathophysiology of ovarian and breast cancer. Clinical cancer research 2007; 13:5745-5755.

16. Comprehensive molecular portraits of human breast tumours. Nature. 2012; 490:61-70.

17. Lee S, Kopp F, Chang TC, Sataluri A, Chen B, Sivakumar $\mathrm{S}, \mathrm{Yu}$ H, Xie Y, Mendell JT. Noncoding RNA NORAD Regulates Genomic Stability by Sequestering PUMILIO Proteins. Cell. 2015.

18. Minn AJ, Gupta GP, Siegel PM, Bos PD, Shu W, Giri DD, Viale A, Olshen AB, Gerald WL, Massague J. Genes that mediate breast cancer metastasis to lung. Nature. 2005; 436:518-524.

19. Dowsett M, Smith IE, Ebbs SR, Dixon JM, Skene A, A'Hern R, Salter J, Detre S, Hills M, Walsh G. Prognostic value of Ki67 expression after short-term presurgical endocrine therapy for primary breast cancer. Journal of the National Cancer Institute. 2007; 99:167-170.

20. Carroll JS, Meyer CA, Song J, Li W, Geistlinger TR, Eeckhoute J, Brodsky AS, Keeton EK, Fertuck KC, Hall GF, Wang Q, Bekiranov S, Sementchenko V, Fox EA, Silver PA, Gingeras TR, et al. Genome-wide analysis of estrogen receptor binding sites. Nature genetics. 2006; 38:1289-1297.

21. Taneja P, Maglic D, Kai F, Zhu S, Kendig RD, Fry EA, Inoue K. Classical and Novel Prognostic Markers for Breast Cancer and their Clinical Significance. Clinical Medicine Insights Oncology. 2010; 4:15-34.

22. Couch FJ, Nathanson KL, Offit K. Two decades after BRCA: setting paradigms in personalized cancer care and prevention. Science. 2014; 343:1466-1470.
23. Harbeck N, Sotlar K, Wuerstlein R, Doisneau-Sixou S. Molecular and protein markers for clinical decision making in breast cancer: today and tomorrow. Cancer treatment reviews. 2014; 40:434-444.

24. van 't Veer LJ, Dai H, van de Vijver MJ, He YD, Hart AA, Mao M, Peterse HL, van der Kooy K, Marton MJ, Witteveen AT, Schreiber GJ, Kerkhoven RM, Roberts C, Linsley PS, Bernards R, Friend SH. Gene expression profiling predicts clinical outcome of breast cancer. Nature. 2002; 415:530-536.

25. Paik S, Shak S, Tang G, Kim C, Baker J, Cronin M, Baehner FL, Walker MG, Watson D, Park T, Hiller W, Fisher ER, Wickerham DL, Bryant J, Wolmark N. A multigene assay to predict recurrence of tamoxifen-treated, node-negative breast cancer. The New England journal of medicine. 2004; 351:2817-2826.

26. Zhao Y, Li H, Fang S, Kang Y, Wu W, Hao Y, Li Z, Bu D, Sun N, Zhang MQ, Chen R. NONCODE 2016: an informative and valuable data source of long non-coding RNAs. Nucleic acids research. 2015.

27. Takagi M, Absalon MJ, McLure KG, Kastan MB. Regulation of p53 translation and induction after DNA damage by ribosomal protein L26 and nucleolin. Cell. 2005; 123:49-63.

28. Gupta RA, Shah N, Wang KC, Kim J, Horlings HM, Wong DJ, Tsai MC, Hung T, Argani P, Rinn JL, Wang Y, Brzoska P, Kong B, Li R, West RB, van de Vijver MJ, et al. Long non-coding RNA HOTAIR reprograms chromatin state to promote cancer metastasis. Nature. 2010; 464:1071-1076.

29. Sorensen KP, Thomassen M, Tan Q, Bak M, Cold S, Burton M, Larsen MJ, Kruse TA. Long non-coding RNA HOTAIR is an independent prognostic marker of metastasis in estrogen receptor-positive primary breast cancer. Breast cancer research and treatment. 2013; 142:529-536.

30. Gokmen-Polar Y, Vladislav IT, Neelamraju Y, Janga SC, Badve S. Prognostic impact of HOTAIR expression is restricted to ER-negative breast cancers. Scientific reports. $2015 ; 5: 8765$.

31. Lu L, Zhu G, Zhang C, Deng Q, Katsaros D, Mayne ST, Risch HA, Mu L, Canuto EM, Gregori G, Benedetto C, $\mathrm{Yu}$ H. Association of large noncoding RNA HOTAIR expression and its downstream intergenic $\mathrm{CpG}$ island methylation with survival in breast cancer. Breast cancer research and treatment. 2012; 136:875-883.

32. Wang K, Guo WX, Li N, Gao CF, Shi J, Tang YF, Shen F, Wu MC, Liu SR, Cheng SQ. Serum LncRNAs Profiles Serve as Novel Potential Biomarkers for the Diagnosis of HBV-Positive Hepatocellular Carcinoma. PloS one. 2015; 10:e0144934.

33. Xu N, Chen F, Wang F, Lu X, Wang X, Lv M, Lu C. Clinical significance of high expression of circulating serum lncRNA RP11-445H22.4 in breast cancer patients: a Chinese population-based study. Tumour biology. 2015; 36:7659-7665. 
34. Lu J, Xie F, Geng L, Shen W, Sui C, Yang J. Investigation of serum lncRNA-uc003wbd and lncRNA-AF085935 expression profile in patients with hepatocellular carcinoma and HBV. Tumour biology. 2015; 36:3231-3236.

35. Deras IL, Aubin SM, Blase A, Day JR, Koo S, Partin AW, Ellis WJ, Marks LS, Fradet Y, Rittenhouse H, Groskopf J. PCA3: a molecular urine assay for predicting prostate biopsy outcome. The Journal of urology. 2008; 179:1587-1592.

36. Gao J, Aksoy BA, Dogrusoz U, Dresdner G, Gross B, Sumer SO, Sun Y, Jacobsen A, Sinha R, Larsson E, Cerami E, Sander C, Schultz N. Integrative analysis of complex cancer genomics and clinical profiles using the cBioPortal. Science signaling. 2013; 6:pl1.

37. Cerami E, Gao J, Dogrusoz U, Gross BE, Sumer SO, Aksoy BA, Jacobsen A, Byrne CJ, Heuer ML, Larsson E, Antipin Y, Reva B, Goldberg AP, Sander C, Schultz N. The cBio cancer genomics portal: an open platform for exploring multidimensional cancer genomics data. Cancer discovery. 2012; 2:401-404.
38. Gray R. A Class of K-Sample Tests for Comparing the Cumulative Incidence of a Competing Risk. The Annals of Statistics. 1988; 16:1141-1154.

39. Pfaffl MW. A new mathematical model for relative quantification in real-time RT-PCR. Nucleic acids research. 2001; 29:e45.

40. Ho TT, Zhou N, Huang J, Koirala P, Xu M, Fung R, Wu F, Mo YY. Targeting non-coding RNAs with the CRISPR/ Cas9 system in human cell lines. Nucleic acids research. 2015; 43:e17.

41. Wong N, Liu W, Wang X. WU-CRISPR: characteristics of functional guide RNAs for the CRISPR/Cas9 system. Genome biology. 2015; 16:218.

42. Ran FA, Hsu PD, Wright J, Agarwala V, Scott DA, Zhang F. Genome engineering using the CRISPR-Cas9 system. Nature protocols. 2013; 8:2281-2308.

43. Wu F, Chiocca S, Beck WT, Mo YY. Gam1-associated alterations of drug responsiveness through activation of apoptosis. Molecular cancer therapeutics. 2007; 6:1823-1830. 